Ethos (Jurnal Penelitian dan Pengabdian Masyarakat):99-104

\title{
Pengaruh Suhu Dan Kelembaban Udara Pada Proses Pengeringan Singkong (Studi Kasus : Pengering Tipe RaK)
}

\author{
${ }^{1}$ Ari Rahayuningtyas, ${ }^{2}$ Seri Intan Kuala \\ ${ }^{1,2}$ Pusat Pengembangan Teknologi Tepat Guna LIPI, JL. K.S Tubun No.5 Subang Jabar \\ e-mail: ${ }^{1}$ arirahayuningtyas@gmail.com, ${ }^{2}$ seri.kuala.sk@gmail.com
}

\begin{abstract}
Abstrak. Salah satu cara untuk memperpanjang daya simpan hasil pertanian adalah dengan pengeringan. Faktor-faktor yang berpengaruh dalam proses pengeringan antara lain suhu, kelembaban udara, laju aliran udara, kadar air awal bahan dan kadar air akhir bahan. Penelitian ini bertujuan untuk mengetahui pengaruh lama waktu pengeringan terhadap perubahan suhu serta kelembaban udara yang terjadi selama proses pengeringan. Metode pengambilan data menggunakan pengambilan data primer yaitu melakukan pengamatan langsung unjuk kerja pengering tipe rak. Suhu ruang pengering diatur antara $50^{\circ} \mathrm{C}-60^{\circ} \mathrm{C}$ dan $60^{\circ} \mathrm{C}-70^{\circ} \mathrm{C}$ dengan kecepatan kipas 2,5 m/dt. Bahan yang dikeringkan berupa irisan singkong setebal $2 \mathrm{~mm}$ dengan berat total $12 \mathrm{~kg}$. Pengamatan terhadap suhu dan kelembaban dilakukan setiap 30 menit selama 3 jam. Dari pengamatan dapat disimpulkan bahwa suhu dan kelembaban sangat mempengaruhi lamanya pengeringan dimana saat kelembaban udara tinggi maka suhu ruangan menjadi rendah yang mengakibatkan waktu pengeringan semakin lama. Begitu pun sebaliknya saat kelembaban udara rendah maka suhu ruangan menjadi tinggi yang mengakibatkan waktu pengeringan menjadi lebih cepat.
\end{abstract}

Kata kunci: suhu, kelembaban, waktu

\section{Pendahuluan}

Pengeringan bahan pangan merupakan salah satu bentuk penanganan pascapanen yang sangat penting. Pengeringan merupakan tahapan operasi rumit yang meliputi perpindahan panas dan massa secara transien serta melalui beberapa laju proses, seperti transformasi fisik atau kimia, yang pada gilirannya menyebabkan perubahan mutu hasil maupun mekanisme perpindahan panas dan massa. Proses pengeringan dilakukan sampai pada kadar air seimbang dengan keadaan udara atmosfir normal (Equilibrium Moisture Content) atau pada batas tertentu sehingga aman disimpan dan tetap memiliki mutu yang baik sampai ke tahap proses pengolahan berikutnya (Widyotomo and Mulato, 2005). Proses pengeringan merupakan proses perpindahan panas dari sebuah permukaan benda sehingga kandungan air pada permukaan benda berkurang (Mahadi, 2007). Sedangkan Brooker et al. (1992) menjelaskan bahwa pengeringan adalah proses perpindahan panas dan perpindahan massa secara bersamaan. Panas diperlukan untuk menguapkan kelembaban yang mengalir dari permukaan produk ke media pengeringan eksternal, biasanya berupa udara. Perpindahan panas dan perpindahan massa yang terjadi selama proses pengeringan merupakan proses yang sangat kompleks karena banyaknya faktor yang dapat mempengaruhi proses tersebut (Sitkei, 1986). Selama proses pengeringan, tidak hanya perpindahan panas yang terjadi tetapi juga adanya penambahan uap air ke udara. Penambahan uap air dari bahan ke udara ini disebabkan oleh perbedaan tekanan uap dimana proses pengeringan terjadi dengan cara penguapan air. Cara ini dilakukan dengan menurunkan kelembaban nisbi udara melalui aliran udara panas atau udara bertekanan sehingga tekanan uap air bahan lebih besar dari tekanan 
uap air udara (Brooker et al., 1981). Kelembaban nisbi membandingkan antara kandungan/tekanan uap air aktual dengan keadaan jenuhnya atau pada kapasitas udara untuk menampung uap air. Kapasitas udara untuk menampung uap air (pada keadaan jenuh) tergantung pada suhu udara. Tingkat kejenuhan sangat dipengaruhi oleh temperatur. Hubungan ketiganya digambarkan dalam dalam Gambar 1.

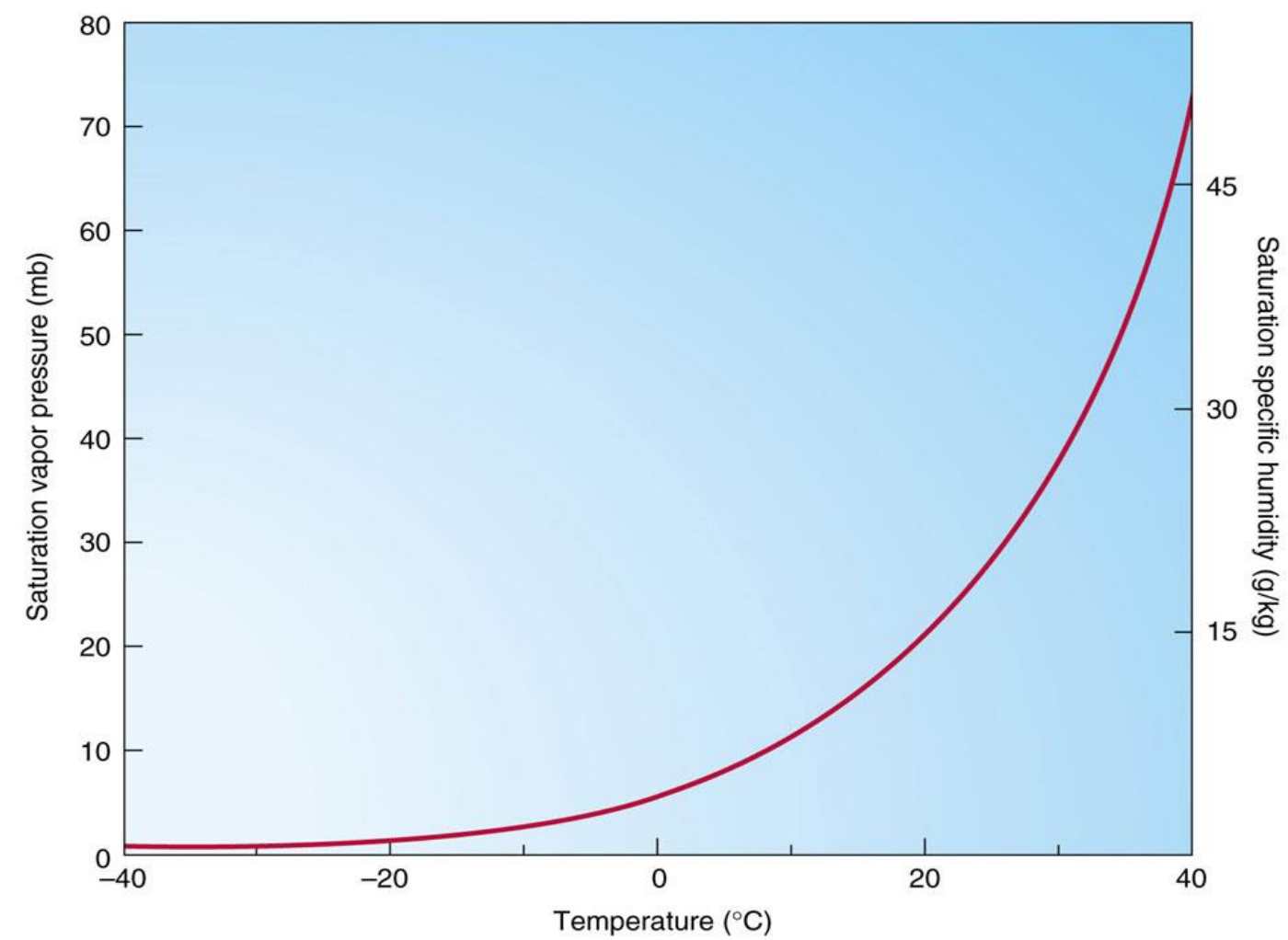

Gambar 1. Hubungan Tekanan Uap Jenuh te rhadap Tempe ratur dan Kele mbaban Spesifikasi Jenuh

Faktor-faktor yang berpengaruh dalam proses pengeringan antara lain suhu, kelembaban udara, laju aliran udara, kadar air awal bahan dan kadar air akhir bahan. Pengeringan secara mekanis dapat dilakukan dengan 2 metode yaitu : Continuous Drying yaitu suatu pengeringan bahan dimana pemasukan dan pengeluaran bahan dilakukan terus menerus. Dan Batch Drying adalah suatu pengeringan dimana bahan masuk ke alat pengering sampai pengeluaran hasil kering, kemudian baru dimasukkan bahan yang berikutnya. Menurut sistem proses pengeringan dibedakan menjadi 2 yaitu : Direct Drying, pada sistem ini bahan dikeringkan dengan cara mengalirkan udara pengering melewati bahan sehingga panas yang diserap diperoleh dari sentuhan langsung antara bahan dengan udara pengering, biasanya disebut pengeringan konveksi. Dan Indirect Drying pada sistem ini panas pengeringan didapat dari dinding pemanas yang bersentuhan dengan bahan yang dikeringkan secara konduksi.

\section{Bahan dan Metode}

Penelitian ini dilakukan di Pusat Pengembangan Teknologi Tepat Guna LIPI Subang, adapun bahan dan metode yang digunakan adalah sebagai berikut: 


\subsection{Bahan}

Bahan pertanian yang digunakan dalam pengambilan data pada proses pengeringan ini adalah singkong yang diambil dari desa Wanareja Kabupaten Subang. Menggunakan sebuah ruang pengering tipe rak ukuran $2 \times 2 \times 2$ m dengan burner gas berbahan bakar LPG, tersusun dari 36 rak, sebuah exhaust fan dan sebuah kipas angin ukuran 12 inchi.

\subsection{Metode}

Metode pengambilan data adalah pengambilan data primer yaitu dilakukan pengamatan langsung pada uji kerja alat pengering. Langkah pertama dilakukan pengupasan kulit kemudian pengirisan singkong berbentuk chip berukuran 1,7 mm selanjutnya dilakukan pengaturan dan pengkondisian ruang pengering pada suhu 50$60^{\circ} \mathrm{C}$ dan $60-70^{\circ} \mathrm{C}$ dengan kecepatan kipas $2,5 \mathrm{~m} / \mathrm{dt}$ serta pengamatan perubahan kelembaban dan suhu ruang pengering mengunakan hygrometer dan termometer raksa. Pengeringan irisan singkong sebanyak $12 \mathrm{~kg}$ sekali proses. Pengamatan suhu dan kelembaban dilakukan setiap 30 menit.

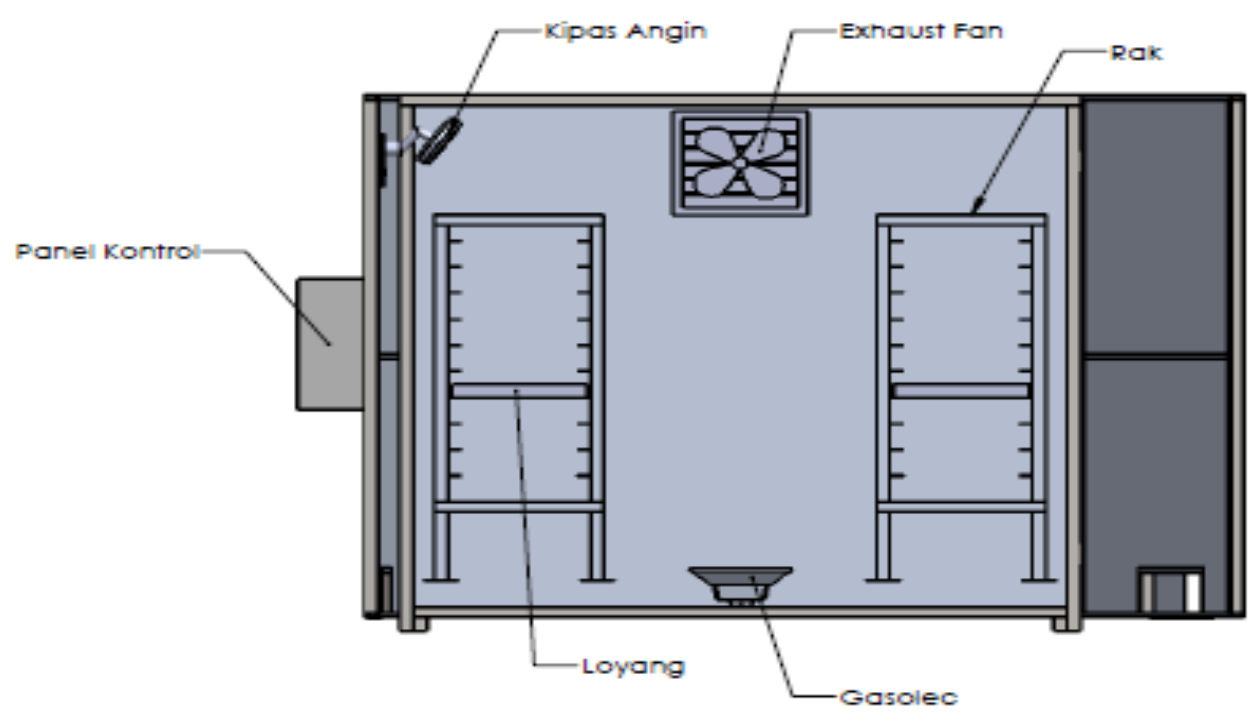

Tampak Depan

\section{Gambar 2. Ruang Pengering Tipe Rak}

\section{Hasil dan Pembahasan}

Dalam pengamatan kali ini suhu diatur antara $50-60^{\circ} \mathrm{C}$ dan $60-70^{\circ} \mathrm{C}$ dengan kecepatan kipas $2,5 \mathrm{~m} / \mathrm{dt}$, produk yang dikeringkan adalah irisan singkong berbentuk chip berdiameter 1,7 mm menggunakan bahan bakar LPG. Nilai suhu ini ditentukan berdasarkan batasan suhu pengeringan bahan makanan yang baik antara $55-75{ }^{\circ} \mathrm{C}$. 
Pengambilan data dilakukan setiap 30 menit. Hal ini dilakukan untuk mengetahui faktor yang berpengaruh dalam proses pengeringan dan difokuskan pada suhu serta kelembaban udara dalam ruang pengering.

Pengamatan pertama hubungan suhu dan kelembaban pada proses pengeringan saat suhu $50-60^{\circ} \mathrm{C}$ terhadap lama waktu pengeringan diperoleh data sebagai berikut:

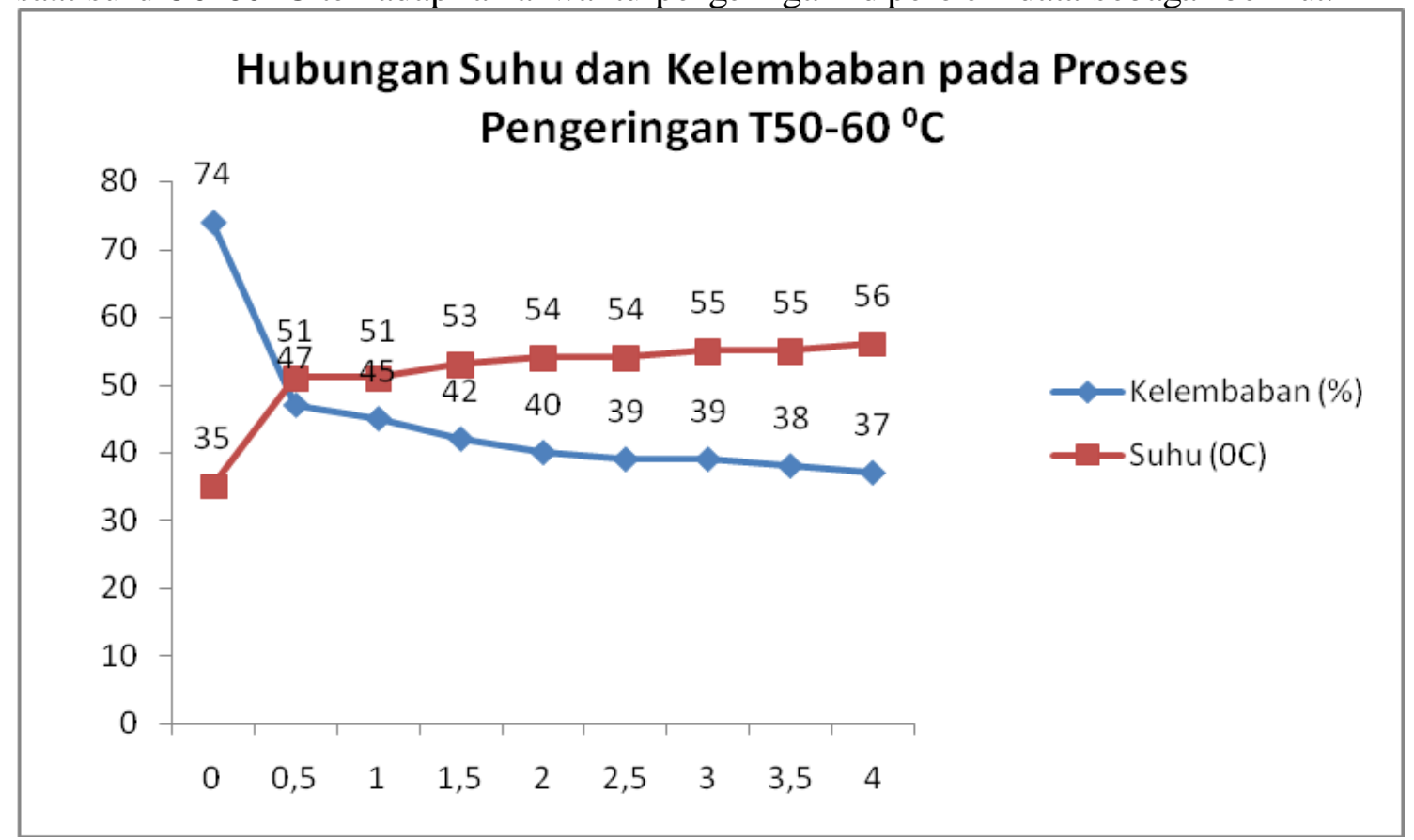

Gambar 3. Hubungan Suhu dan Kelembaban pada Proses Pengeringan T $=50-60^{\circ} \mathrm{C}$ te rhadap Lama Waktu Pengeringan

Pada gambar 3 terlihat bahwa pada pengamatan waktu ke 0 menit, kelembaban awal adalah $74 \%$, pada 30 menit pertama terjadi penurunan kelembaban hingga mencapai 47\%, 30 menit kemudian sebesar 45\%, 42\%, 40\%, 39\%, 39\%, 38\% dan 37\%. Hal ini tampak bahwa semakin lembab udara di dalam ruang pengering maka akan semakin lama waktu proses pengeringan berlangsung dengan rata-rata penurunan kelembaban setiap 30 menit kurang lebih sebesar 4\%. Untuk suhu saat pengamatan waktu ke 0 menit, suhu awal adalah $35^{\circ} \mathrm{C}$, pada 30 menit pertama terjadi kenaikan suhu menjadi $51^{\circ} \mathrm{C}, 30$ menit kemudian sebesar $51^{\circ} \mathrm{C}, 53^{\circ} \mathrm{C}, 54^{\circ} \mathrm{C}, 54^{\circ} \mathrm{C}, 55^{\circ} \mathrm{C}, 55^{\circ} \mathrm{C}$ dan $56^{\circ} \mathrm{C}$. Hal ini nampak bahwa seiring pertambahan waktu, suhu dalam ruang pengeringan menjadi lebih tinggi dengan rata-rata kenaikan suhu setiap 30 menit kurang lebih sebesar $2^{\circ} \mathrm{C}$. 


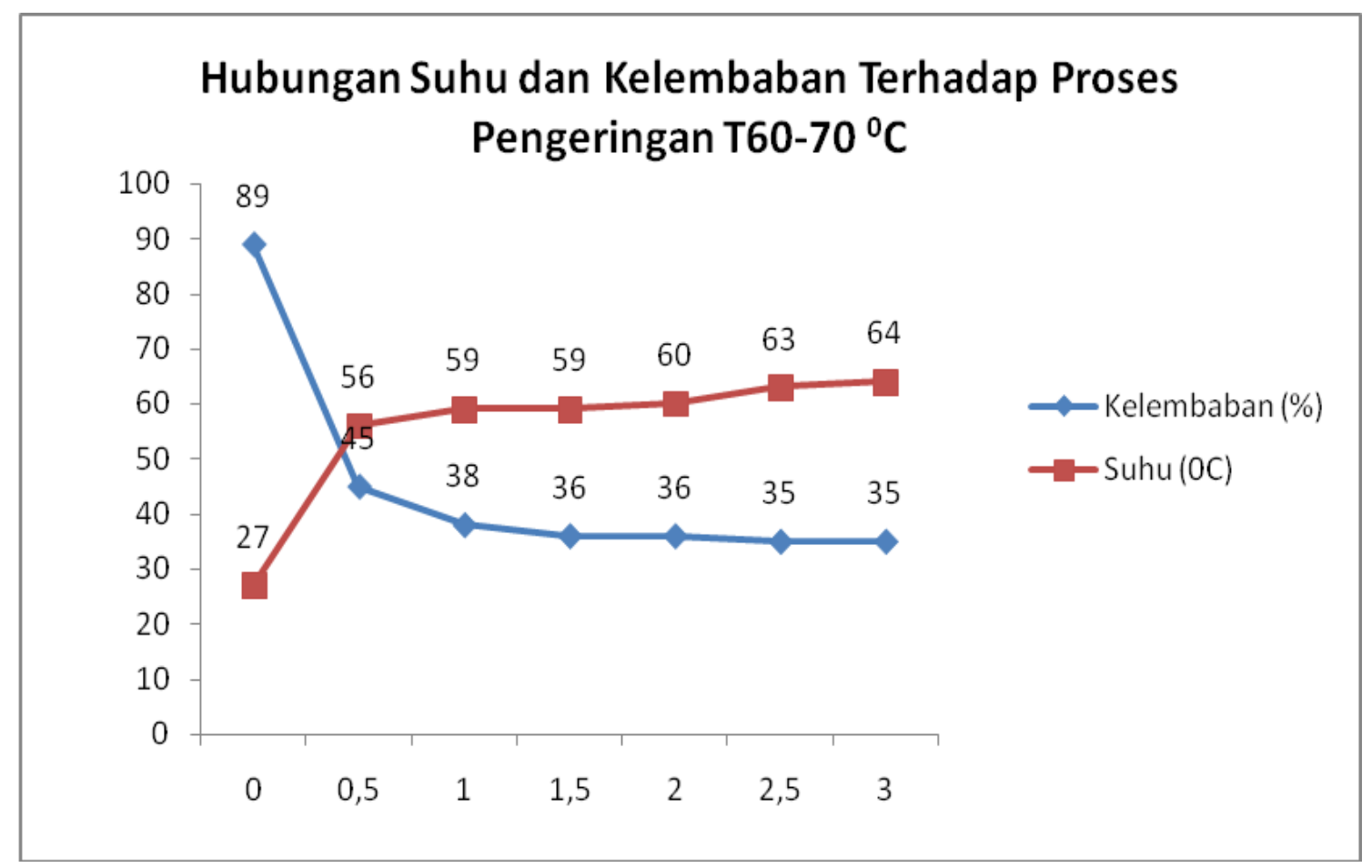

Gambar 4. Hubungan Suhu dan Kelembaban pada Proses Pengeringan $\mathrm{T}=60-70^{\circ} \mathrm{C}$ terhadap Lama Waktu Pengeringan

Pada gambar 4 terlihat bahwa pada pengamatan waktu ke 0 menit, kelembaban awal adalah $89 \%$, pada 30 menit pertama terjadi penurunan kelambaban hingga mencapai kelembaban 45\%, 30 menit kemudian sebesar 38\%, 36\%, 36\%, 35\% dan $35 \%$. Hal ini tampak bahwa semakin lembab udara di dalam ruang pengering maka akan semakin lama waktu proses pengeringan berlangsung dengan rata-rata penurunan kelembaban setiap 30 menit sebesar kurang lebih 9\%. Untuk suhu saat pengamatan waktu ke 0 menit, suhu awal adalah $27^{\circ} \mathrm{C}$, pada 30 menit pertama terjadi kenaikan suhu menjadi $56^{\circ} \mathrm{C}, 30$ menit kemudian sebesar $59^{\circ} \mathrm{C}, 593^{\circ} \mathrm{C}, 60^{\circ} \mathrm{C}, 63^{\circ} \mathrm{C}$, dan $64^{\circ} \mathrm{C}$. Hal ini nampak bahwa seiring pertambahan waktu suhu dalam ruang pengeringan menjadi lebih tinggi dengan rata-rata kenaikan suhu setiap 30 menit sebesar kurang lebih $6^{\circ} \mathrm{C}$.

\section{Kesimpulan}

Faktor-faktor yang berpengaruh dalam proses pengeringan antara lain adalah suhu, kelembaban dan waktu. Semakin besar perbedaan suhu (antara medium pemanas dengan bahan) maka akan semakin cepat proses pindah panas berlangsung sehingga mengakibatkan proses penguapan semakin cepat pula. Semakin lembab udara di dalam ruang pengering maka akan semakin lama proses pengeringan berlangsung kering, begitu juga sebaliknya.

\section{Ucapan Terimakasih}

Terimakasih kepada tim Bengkel Mekanik Logam, Mahasiswa magang dari Universitas Lampung, tim perancangan Pusat Pengembangan Teknologi Tepat Guna dan segenap pihak yang terlibat dan telah membantu serta mendukung berjalannya penelitian ini. 
104 Ari Rahayuningtyas, et al

\section{Daftar Pustaka}

Brooker, D. B., F. W. Bakker-arkema and C. W. Hall. 1981. Drying Cereal Grains. Avi Publishing Company Inc. West Port, Connecticut.

Brooker, D. B., F. W. Bakker-arkema and C. W. Hall. 1992. Drying and Storage of Grains and Oilseeds. Avi Published by Van Nostrand Reinhold, New York, USA.

Kartasapoetra, A.G. 1994. Teknologi Penanganan Pasca Panen. PT Rineka Cipta. Jakarta.

Mahadi. 2007. Model Sistem dan Analisa Pengering Produk Makanan. USU Repository. Universitas Sumatera Utara.

Sitkei, György. 1986. Mechanics of Agricultural Materials. Developments in Agricultural Engineering 8. Elsevier Science Publishers. Budapest, Hungary.

Widyotomo, S. dan Sri Mulato. 2005. Penentuan Karakteristik Pengeringan Kopi Robusta Lapis Tebal. Study of Drying Characteristic Robusta Coffe with Thick Layer Drying Method. Buletin Ilmiah INSTIPER Vol. 12, No. 1, Page 15-37. 